\title{
The principal characterized features of earth's crust within regional strike-slip zones
}

\author{
Aleksei Ageev \\ Ph.D, Assistant Professor, St. Petersburg Mining University, Saint-Petersburg, Russia \\ Aleksei Egorov \\ Doctor of Sciences, head of the Geological Department, St. Petersburg Mining University, \\ Saint-Petersburg, Russia \\ Nikita Krikun \\ Ph.D student, St. Petersburg Mining University, Saint-Petersburg, Russia
}

\begin{abstract}
Strike-slip zones are very important geological planet-scale structures. Scientific interest in studying these zones connects with frequent natural hazard (earthquakes, land-slides etc.). Moreover, active tectonics provide a high potential for mineral deposit surveys. This article is a first one in a series of articles and show the main result of modern surface structure of Earth's crust of Baikal-Stanovaya strike-slip zone. Before start, we examined results of geological and geophysical investigation of the earth's crust within most studied strike-slip zone all over the World (San Andreas and Upper-Rhine Graben). It helped us to create an algorithm of comprehensive research of crust investigated region. This algorithm consists from 3 stage. First step was accumulated geological-geophysical information about Earth's crust. At the next step we calculated transformation of geophysical potentional fields and conducted lineaments analysis. The final step was focused on compared individual lineament's schemes with geological maps and created a general tectonic scheme of Baikal-Stanovaya regional strike-slip zone.
\end{abstract}

\section{INTRODUCTION}

Regional Strike-slip Zones (RSZ) are geological structures of a planetary scale. The study of their modern structure, deep structure and evolution are fundamental tasks of modern geotectonics. High level of crust's destruction influences on minerogenic survey and metallogeny mapping (Nikolaeva, 2019). World experience in the study of new geological structures indicates that the analysis of the results of comprehensive work on the most studied strike-slip zones of the world plays an important role in the research process. Such comparison is possible only in the course of a model that considers the difference in the geodynamic parameters of the structures under study. In the research process, the authors chose a generalized "zonalblocking geotectonic model of the earth's crust" (Egorov A.S., Gulin V.D., 2014). The main structural units in this model are blocks with continental, oceanic and transitional types of crusts (areas of stationary geophysical parameters) and interblock zones (gradient zones of geophysical parameters, high seismicity and high heat flow). In that case, interblock zones correspond to suture zones, rifts, tectonic dislocations systems and main faults. The number of faults and the value of tectonic stresses within the interblock zones are several times higher than in the internal areas of relatively stationary blocks.

Nowadays, the most detail-studied by complex geological and geophysical methods is the San Andreas faults system. This tectonic zone is considered as the boundary between the North American craton and the Pacific lithospheric plate. Scientists attribute its foundation to a change in the geodynamic situation on the western edge of the North American continent 
from subduction to transform, which occurred in the Paleogene (Armstrong, Ward, 1991; Humphreys, 2003). Currently, the dextral strike-slip component predominates in the San Andreas fault system.

\section{DATA \& METHODS}

The results of comprehensive studies show that the highly seismic strike-slip zone of San Andreas is an extremely complex geological structure. The crust is characterized by a zonalblocking structure which was mapped during geological and geophysical investigations. The main tectonic units are large crustal blocks of the Pacific and North American plates: Great Valley, Mojave, Transverse Ranges, etc. (Figure 1) Their interaction occurs according to a well-developed system of tectonic dislocations which form 3 spatially joint interblock zones (San Andreas, Walker Lane, East California Shear Zone). The most structural controlling dislocation within San Andreas interblock zone is the San Andreas fault. The large part of tectonic stresses from the plate's interaction are indicating along the main fault. San Andreas fault is a very contrast structure. In potential geophysical fields it corresponds to highgradient zones. On LANDSAT images and 3D models of relief - straightened areas (10 $50 \mathrm{~km}$ length). Nearby the San Andreas fault develop numerous of secondary faults, which also seismogenic. Geological data show that these secondary faults play a key role in joining San Andreas zone with adjustments interblock zones. Results of detailed investigations of Walker Lane and ECSZ show well-developed fault systems with a network of spatially interconnected dislocations within zones. The main fault was not mapped in both structures.

The most studied trans-regional strike-slip zone in Europe is the Upper Rhine Graben (Germany). This tectonic zone bounds by the Rhine massif from the north and by the Swiss Alps

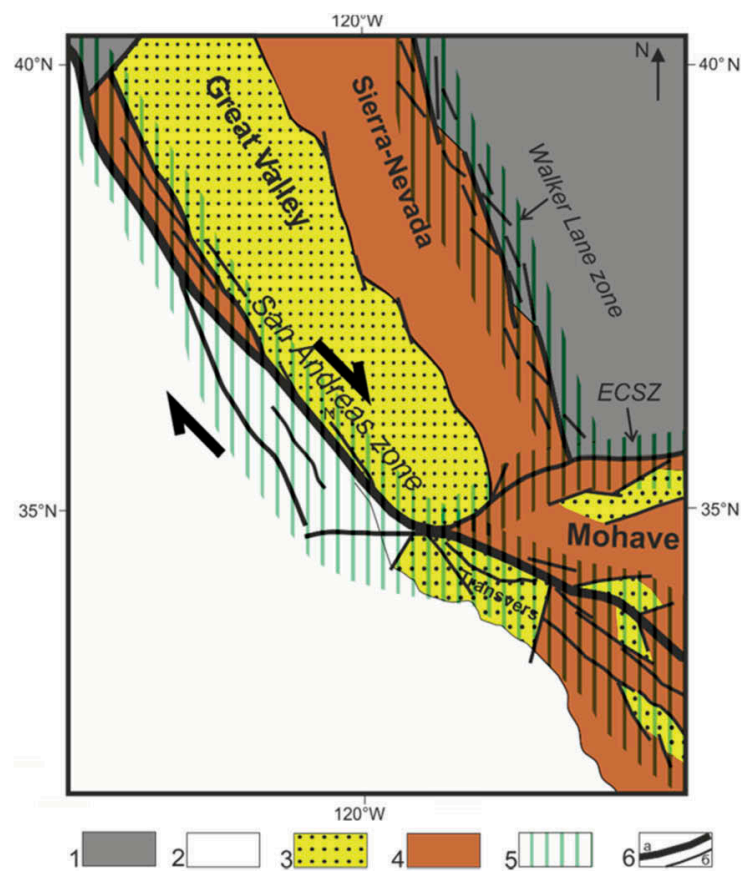

Figure 1. Tectonic scheme of the San Andreas zone.

Legend:1-2 - Lithospheric plates: 1 - North American continental plate; 2 - Pacific Ocean plate; 3-4 Alpine orogeny stationary blocks with transition type of crust: 3 - Basement covers Tretiary sediments, 4 - Basement covers volcanic sediments; 5 - Interblock zones; 6 - Faults. 
from the south (Grimmer, 2017). It is the most seismically active part of the European Cenozoic Rift System. Graben is located in its southern part of it.

The results of geological and geophysical studies show that the crust of this region can be interpreted by a zonal-blocking model. Large blocks of the continental crust are mapped: Moldanubian, Black Forest, Saxon-Thuringian and Swabian (Figure 2). The interblock zone is represented by two elongated "boundary" tectonic faults and a numerous of secondary dislocations (Fracassia, 2005). Researchers in this region identify "boundary" faults as the main structure controlling faults with dominant sinistral kinematics.

These faults mapped by geological surveys and characterize clearly visible structures on remote sensing data. Moreover, these faults correspond to high-gradient zones in potential geophysical fields. "Boundary" faults have a developed system of secondary dislocations. The fault branches extend outside the graben and to its inner region. Both "boundary" and intragraben faults are seismogenic but the intragraben faults mostly correspond normal-fault kinematics.

Scientific results of investigation earth's crust structure of San Andreas and Upper-Rhine Graben help us in studying of a strike-slip zone which develop in the territory of the Russian Federation.

The Neogene-Quaternary Baikal-Stanovaya regional strike-slip zone. It extends for more than 1,500 km east-northeast of Lake Baikal to coastline the Sea of Okhotsk (Ageev, 2016). Large crust geoblocks of the Siberian craton and the Ural-Mongolian ranges belt are most important geological structure of this region.

Research within the San Andreas and the Upper Rhine Graben showes that the first phase of a comprehensive study of the crust should be the spatial modelling of tectonic faults on the surface. In that case, authors formed a geospatial database of geological, geophysical seismological and remote sensing data. The geodatabase was created by ArcGIS 10.3 software, that provided more mobility sharing and updating the database during the research. Information was separated depend on physical properties which data contained. The scale of maps was

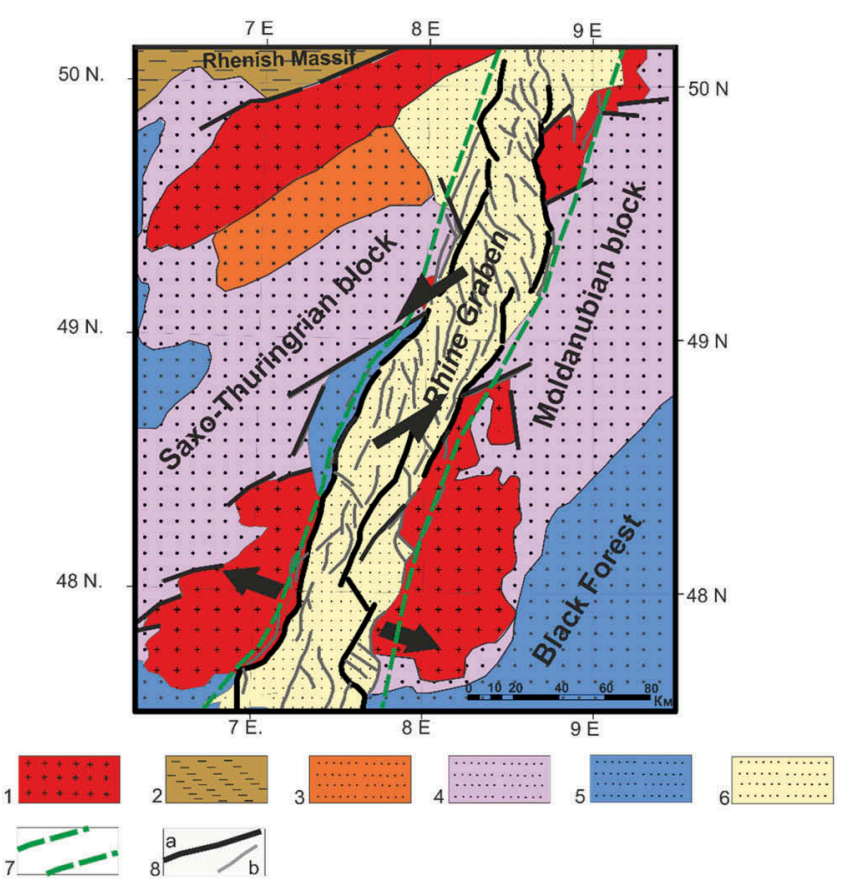

Figure 2. Tectonic scheme of the upper Rhine Graben zone.

Legend: 1 - Variscan crystalline basement; 2 - Devonian sediments; 3 - Permian sediments; 4 - Carboniferous sediments; 5 - Jurassic sediments; 6 - Tertiary sediments; 7 - Interblock zone; 8 -Faults: a - "borders", $\mathrm{b}$ - secondary faults. 
also important. In that case, we decided to divide all geodata for subdivisions: small-scale; middle-scale and large-scale formats. Small-scale format of data includes: Geological Map of Russia Federation and Adjacent Areas 1:2 500 000; Atlas of Geological Maps of Asia and Adjacent Areas; Tectonic Map of Northern, Central and Eastern Asia; The Atlas of summary maps of the territory of Russia; Map of Active Faults of Russia; In the second group were selected: Geological and Geophysical Maps 1:1 000000 (lists: O49 - O52; N49 - N52) from All-Russian Geological Institute (VSEGEI);

The main aspect in modeling the lateral distribution of tectonic dislocations were two types of independent lineament analysis: by user (visually) and by computer (PCI Geomatica software). The computer lineament analysis was used only in difficult geological situation and along geotraverses.

The whole complex of georeferenced and systematized geodata was involved in the data process. The most important source for lineaments analysis was satellite images (combined Landsat and visual model of relief). This image covers all investigated region from the lake of Baikal to coastline of the Okhotsk sea. The key features which we tried to identify were straight sections. Mostly it connected with rivers or specific landscape features. At the next step we conducted a lineament analysis of the initial potential geophysical fields (magnetic and gravity fields). The transformants (horizontal and full gradients) were also calculated and have been analyzed. Results of spatial distribution of the earthquake helped in lineament's quality. The catalog of seismic events in the south of the Siberian Platform for the period of instrumental observations from 1960 to 2019 was used in research (U.S. Geological Survey, 2019). The mistake in spatial position of earthquake estimates 1-3 km. In that case the earthquakes data plays secondary role in analysis.

At the first stage of data process we combined georeferenced individual lineaments patterns between each other. Lineaments that were not confirm at least two independent data sources removed from data process. Comparison of georeferenced lineament's schemes conducted in ArcGIS. These procedures led us to reduce a number of lineaments and helped in creation a general scheme of lineaments. The last step was focused on comparison a general lineament pattern with geological, tectonic and active faults schemes. In that case inconsistent lineaments were also deleted.

\section{RESULTS}

As a result of the studies, a tectonic scheme of the region was compiled. This map shows the zonal-blocking structure of the earth's crust. Several large crustal blocks are identified. A comparison of geophysical fields' linear features, other maps and diagrams made it possible to map and trace spatially interconnected systems of faults and independent faults through the area. Fault systems form an interblock zone, which develops from the southern end of Lake Baikal, then is mapped within the Baikal-Vitimskaya zone, and Khilock-Vitimskiy and Shilkinsky blocks and traces to the east, separating the Aldan and Stanovoy blocks. It should be noted that the main fault does not identified as a single structure. But, a large number of secondary faults are mapped. These faults mostly have echelon and linear form. It can be considered as tectonic "joints" between segments and systems of faults. Most of these faults system form Quaternary and Jurassic depressions. A general shape of interblock zone indicate a bend in a central part of it. In that area we mapped spatial connections with Mongol-Okhotskaya shear zone by group of faults. This situation is similar to San Andreas and adjacent interblock zones. The Mongol-Okhotskaya shear zone older than Baikal-Stanovaya but it also should be investigated in future research.

\section{DISCUSSION}

The results of the study show that using the model of the zonal-blocking structure of the earth's crust, it is possible to investigate different geodynamic regional strike-slip zones. The main geological units within these structures are blocks and interblock zones. The crust of the 


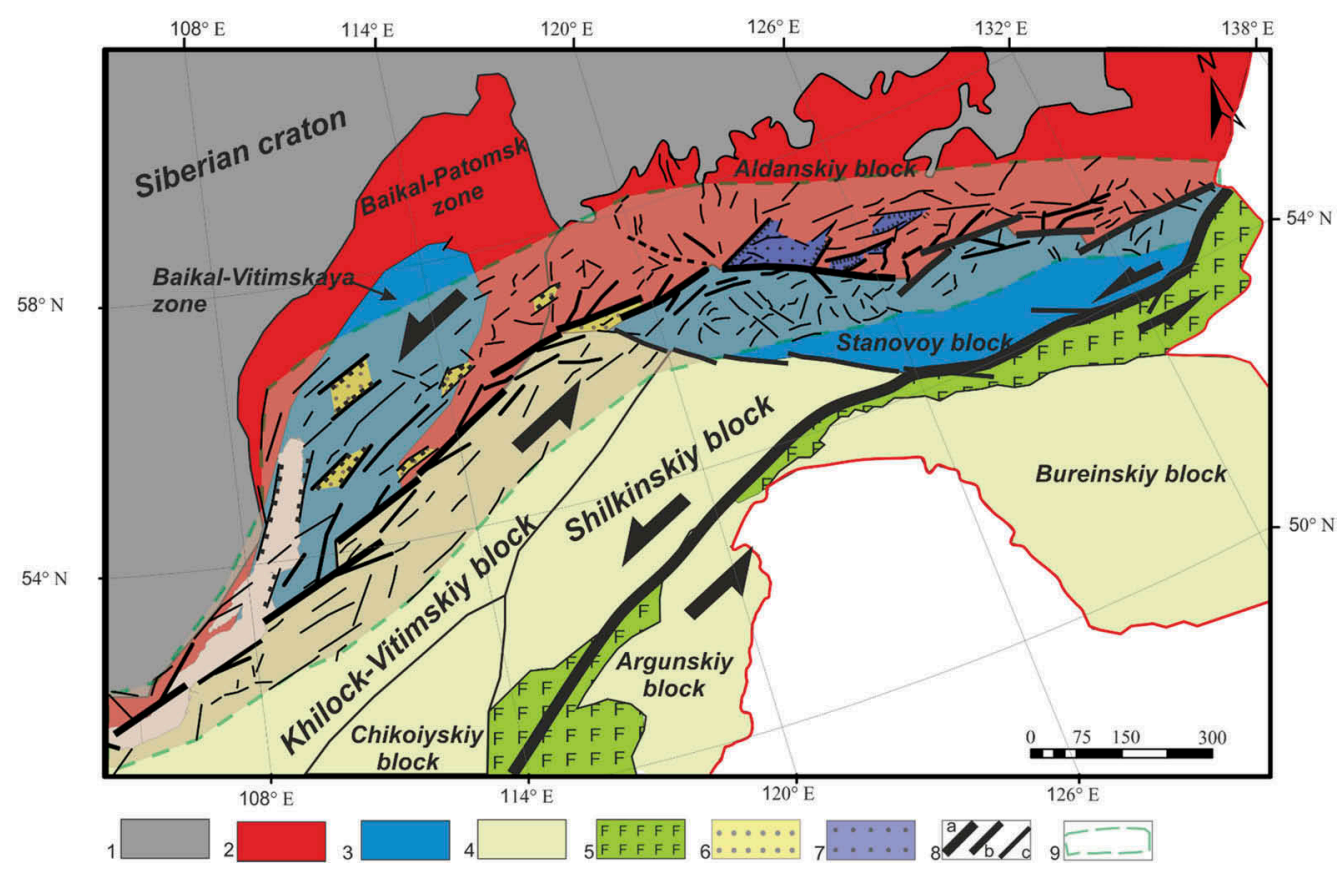

Figure 3. Tectonic scheme of Baikal-Stanovaya strike-slip zone.

Legend: 1 - Continental bocks with Archean basement; 2 - Deformed margins of Archean continental blocks; 3 - Blocks with Caledonian crystalline basement; 4 - Blocks with Cimmerian basement; 5 - Ophiolites; 6 - Neogene-Quaternary basins; 7 - Jurassic basins; 8 - Faults: a -segments of main fault, $b$-secondary faults with strike-slip kinematics, $\mathrm{c}$ - secondary faults with unknown kinematics; 9 - Interblock zone

interblock zones is characterized by the largest number of tectonic dislocations which form spatially interconnected fault systems. It was shown that the shape, quantity, and geographical distribution ensembles of tectonic dislocations within the strike-slip zones are different. These parameters depend on and mainly determined by a value and direction of the vectors of main and local tectonic stresses (Figure 3).

\section{REFERENCES}

Ageev, A.S., Ilalova, R.K., Duryagina, A.M. \& Talovina, I.V. 2019. A link between spatial distribution of the active tectonic dislocation and groundwater water resources in the Baikal-Stanovaya zone. Mining Informational and Analytical Bulletin V.5: 173-180. DOI: 10.25018/0236-1493-2019-050-173-180.

Armstrong, R.L \& Ward, P. 1991. Evolving geographic patterns of Cenozoic magmatism in the North America Cordillera: The temporal and spatial association of magmatism and metamorphic core complexes. J. Geophys. Res.V.96: P.13201-13224. DOI: 10.1029/91JB00412.

Egorov, A.S \& Gulin, V.D. 2014. Geological and geophysical deep structure researches of northern Eurasia in the zone-block model of the earth's crust. 6th Saint Petersburg International Conference and Exhibition on Geosciences: Investing in the Future 2014: 133-137. DOI: https://doi.org/10.3997/22144609.20140220.

Fracassia, U., Niviere, B. \& Winter, T.First. 2005. Appraisal to define prospective seismogenic sources from historical earthquake damages in southern Upper Rhine Graben. Quaternary Science Reviews V.24: 403-425.

Grimmer, J.C., Ritter, J.R., Eisbacher, G.H. \& Fielitz, W. 2017. The Late Variscan control on the location and asymmetry of the Upper Rhine Graben. International journal of Earth Sciences № 106: 827853. DOI: $10.1007 / \mathrm{s} 00531-016-1336-x$. 
Humphreys, E, Hessler, E., Dueker, K., Farmer, G., Erslev, E. \& Atwater, T. 2003. How Laramide-Age Hydration of North American Lithosphere by the Farallon Slab Controlled Subsequent Activity in the Western United States. In: The lithosphere of Western North America and its geophysical characterization. Klemperer S.L., Ernst W.G. (Eds.), Bellwether Publishing. Ltd. For the Geological Society of America. The George A. Thompson Volume International Book Series Volume 7: 524-544. DOI: $10.2747 / 0020-6814.45 .7 .575$.

Nikolaeva, E., Talovina, I, Duriagina, A., Vorontcova, N., Krikun, N. 2019. The Main Factors Influencing of Minor Intrusions on the Formation of Nickeliferous Weathering Crust on the Example of the Sakhara and the Elov Deposits (Urals). 19th International Multidisciplinary Scientific GeoConference SGEM 2019 Vol.18, Issue 1.1: 625-630. Bulgaria: SGEM 2019 Conference Proceedings. ISBN 978619-7408-76-8.

U.S. Geological Survey. 2018. 2017, Earthquake Facts and Statistics: accessed March 22 at URLhttps:// earthquake.usgs.gov/earthquakes/browse/stats.php (last accessed 20.01.2020). 